Review

\title{
Proton Pump Inhibitors in Veterinary Medicine
}

\author{
${ }^{1}$ Oguzhan Yavuz and ${ }^{2}$ Handan Hilal Arslan \\ ${ }^{I}$ Department of Pharmacology and Toxicology, \\ Faculty of Veterinary Medicine, Ondokuz Mayis University, Samsun, Turkey \\ ${ }^{2}$ Department of Internal Medicine, Faculty of Veterinary Medicine, Ondokuz Mayis University, Samsun, Turkey
}

\author{
Article history \\ Received: 01-04-2017 \\ Revised: 02-06-2017 \\ Accepted: 23-06-2017 \\ Corresponding Author: \\ OguzhanYavuz \\ Department of Pharmacology \\ and Toxicology, Faculty of \\ Veterinary Medicine, \\ OndokuzMayis University, \\ Samsun, Turkey \\ Tel: 00903623121919/2830 \\ Fax: 00903624576922 \\ E-mail: oguzhany@omu.edu.tr
}

\begin{abstract}
Inhibition of gastric acid secretion is necessary to treat many gastrointestinal diseases. Proton Pump Inhibitors (PPIs) are very effective drugs, used for gastric acid inhibition and therapy of important erosive and non-erosive gastrointestinal disorders in animals as well as humans. In this review, general properties of PPIs, their mode of action, pharmacokinetics, efficacy, adverse effects, drug interactions and clinical and alternative uses in veterinary medicine were evaluated.
\end{abstract}

Keywords: Gastrointestinal Disorders, Proton Pump Inhibitors, Veterinary Medicine

\section{Introduction}

Gastric acid is the secretion of parietal cells of stomach and it is controlled by paracrine, endocrine and neuronal systems. An important enzyme, $\mathrm{H}^{+} / \mathrm{K}^{+}$ATPase, is the main actor to pump hydrogen ions into the stomach lumen $\left(\mathrm{H}^{+} / \mathrm{K}^{+}\right.$proton pump) (Shin and Sachs, 2008; Hori et al., 2011; Garcia-Mazcorro et al., 2012). The Proton Pump Inhibitors (PPIs) provide an irreversible inhibition of the gastric pump in parietal cells (Papich, 2009; Kosma et al., 2016).

Thanks to this effect, PPIs are widely used for treatment of many erosive and non-erosive gastrointestinal disorders, such as peptic ulcers, Gastro-Oesophageal Reflux Disease (GERD), Barrett's oesophagus, ZollingerEllison syndrome, dyspepsia and Helicobacter pylori infection in humans and different animal species (Shin and Sachs, 2004; 2008; Papich, 2009). The pharmacological acid suppression in these diseases, especially in ulcers and GERD, causes very important benefits, such as abolition of elective surgery and reduction in non-steroidal anti-inflammatory drugs-associated gastropaties (Scarpignato and Pelosini, 2006).

The first registered PPI is omeprazole for humans in 1989. Afterwards, lansoprazole, rabeprazole, pantoprazole, esomeprazole and tenatoprazole were released to the market. Clinical usage of PPIs dramatically increased year by year in humans and animals (Papich, 2009; Ortiz de Garcia et al., 2014; Kosma et al., 2016).
All clinically used PPIs contain a pyridyl methylsulfinyl benzimidazole group and differ only type of substituents on the pyridine and benzimidazole rings (Kosma et al., 2016). Some important physicochemical properties of PPIs are shown in Table 1.

\section{Mode of Action}

The gastric $\mathrm{H}^{+} / \mathrm{K}^{+}$ATPase is in the cytoplasmic tubuler membranes of the parietal cells in the resting state. After the activation of the parietal cells by a stimulant (acetylcholine, histamine etc.), $\mathrm{H}^{+} / \mathrm{K}^{+}$ ATPase appears to be in the microvilli of the expanded secretory canalicus and an ATP-dependent hydrogen-potassium exchange and gastric acid secretion occurs (Shin and Sachs, 2008).

PPIs are weak bases and potent acid suppressing prodrugs. Due to their weak base features (pKa 1 values are between 3.8 and 4.9), they can accumulate in the acidic environment of the secretory canalicus of the parietal cells. In this compartment, PPIs becomes active after two protonation (pyridine and benzimidazole). Protonated drug split to sulfenic acid and sulfenamide active forms. Sulfenamide covalent binds to $\mathrm{H}^{+} / \mathrm{K}^{+}$ ATPase and the effect occurs (Shin et al., 2006; Papich, 2009; Huttunen et al., 2011). Conversion of omeprazole to sulfenamide in the parietal cells and covalent interaction of sulfenamide to $\mathrm{H}+/ \mathrm{K}+$ ATPase are shown in Fig. 1. 
Table 1. Important physical and chemical properties of PPIs

Pantoprazole

Table 2. Clinical use of PPIs in veterinary medicine

\begin{tabular}{|c|c|c|c|}
\hline Gastrointestinal disorder & PPI & Animal species & Treatment \\
\hline \multirow[t]{6}{*}{ Gastric ulcers } & Omeprazole & Dog & $0.5-1 \mathrm{mg} / \mathrm{kg} /$ day PO (total $20 \mathrm{mg}^{-1}$ ) \\
\hline & & Cat & $0.5-1.5 \mathrm{mg} \mathrm{kg}^{-1}$ once or twice a day \\
\hline & & Horse & $4 \mathrm{mg} / \mathrm{kg} /$ day PO for treatment (4 weeks) \\
\hline & & & $2 \mathrm{mg} / \mathrm{kg} /$ day PO for prevention \\
\hline & & Swine & $40 \mathrm{mg}^{-1}$ total \\
\hline & Pantoprazole & Dog/Cat & $0.5-1 \mathrm{mg} / \mathrm{kg} /$ day IV \\
\hline \multirow[t]{2}{*}{ Acute gastritis } & Omeprazole & Dog/Cat & $0.7-2 \mathrm{mg} / \mathrm{kg} /$ day PO \\
\hline & Pantoprazole & Dog/Cat & $1 \mathrm{mg} / \mathrm{kg} /$ day IV \\
\hline Helicobacter pylori & Omeprazole & Dog & $\begin{array}{l}0.66 \mathrm{mg} / \mathrm{kg} / \mathrm{day} \text { (combination with amoxicillin or tetracycline, } \\
\text { metronidazole and bismuth subsalicylate) for } 2-3 \text { weeks }\end{array}$ \\
\hline \multirow[t]{2}{*}{ Abomasal ulcers } & Omeprazole & Ruminants & $2 \mathrm{mg} \mathrm{kg}^{-1} \mathrm{IV}$ \\
\hline & & Milk-fed calves & $4 \mathrm{mg} \mathrm{kg}^{-1} \mathrm{PO}$ \\
\hline
\end{tabular}

\section{Pharmacokinetics}

After the oral administration, PPIs are rapidly and highly absorbed in the small bowel. Approximately $70 \%$ of omeprazole is absorbed from the gastrointestinal system. An acidic $\mathrm{pH}$ in the parietal cells is required for activation of PPIs and food stimulates acid production. Therefore, PPIs should be administered about 30 min before meals and feeding. PPIs are highly protein bound drugs. Omeprazole extremely (95\%) binds to plasma proteins, $\alpha_{1}$-acid glycoprotein and albumin. It reaches plasma peak concentration within 30-120 min in humans. Volume of distribution values $0.3 \mathrm{~L} \mathrm{~kg}^{-1}$ in humans and excretion half-life is about $50 \mathrm{~min}$ in humans and 30 min in dogs. (Kaya, 2007; Wallacei and Sharkey, 2011; Kosugi et al., 2015).

PPIs are rapidly and broadly metabolized by hepatic cytochromes (CYPs). Especially, CYP2C19 and CYP3A4 have important roles in the biotransformation of PPIs. Several metabolites were determined for each PPI, for example at least six metabolites of omeprazole were identified. The main excretion route is urine; however they are also eliminated by excretion in the bile (Kaya, 2007; Wallacei and Sharkey, 2011; Zullo et al., 2012; Kosma et al., 2016). 


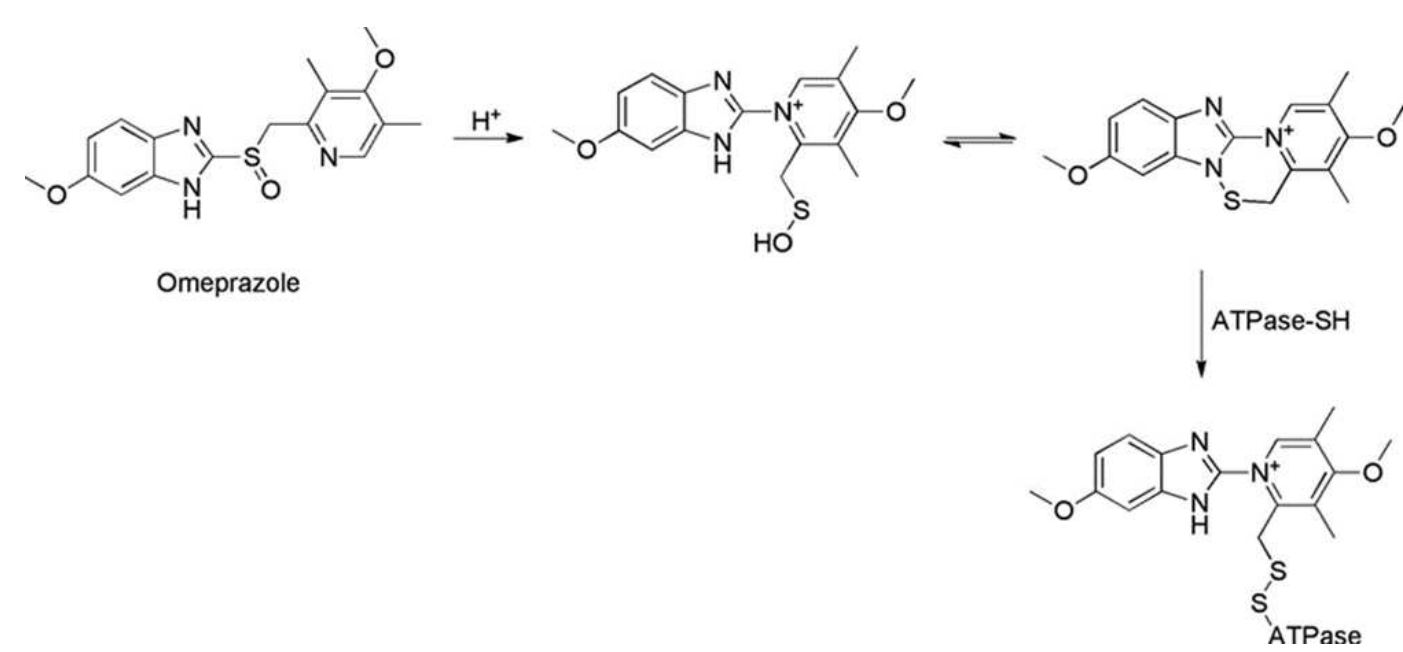

Fig. 1. Conversion of omeprazole to sulfenamide in the parietal cells and covalent interaction of sulfenamide in the proton pump (Huttunen et al., 2011)

\section{Efficacy}

The $\mathrm{H}^{+} / \mathrm{K}^{+}$ATPase is the last stage of the gastric acid secretion. Therefore, PPIs are accepted as more effective than receptor antagonists in suppressing gastric acid secretion (Shin and Sachs, 2008; Papich, 2009). It was reported that PPIs are 10-30 times potent acid suppressing drugs than cimetidine. Therefore, PPIs are evaluated as a superior alternative to $\mathrm{H}_{2}$ receptor antagonists and other anti-secretory drugs for treatment and prevention of ulcers caused by NSAIDs, some other types of ulcers, esophagitis and H. pylori. Many studies showed that there are no differences in efficacy among PPIs (Kaya, 2007; Papich, 2009). However, some researchers reported that esomeprazole and tenatoprazole are more effective with a longer period for the acid suppression (Liu et al., 2007; Shin and Sachs, 2008).

The efficacy of PPIs depends on their covalent binding to the pump and therefore their effect is longer than their plasma residence time above minimum effective level, which is about $10-120 \mathrm{~min}$.

An important point for the activation of PPIs is that the parietal cells of stomach have to secret the gastric acid at the time of the administration. Therefore, PPIs cannot inhibit all gastric acid pumps with oral dosing, because all pumps are not active during the 90-min halflife of many PPIs (except tenatoprazole, its half-life is 9 h). Because of short half-life of PPIs only $70 \%$ of the pump enzymes can be inhibited. Especially, due to all pumps are not activated by breakfast or other meals and the cumulative effect of PPIs, reaching steady state inhibition of the acid secretion on once a day administration takes about 2-3 days. Increasing of the dose has virtually no effect after the optimal dosage (Shin and Sachs, 2004; 2008; Shin et al., 2006).

Another problem is the fast reversal of the acid secretion. After omeprazole treatment, gastric acid secretion and $\mathrm{H}^{+}, \mathrm{K}^{+}$-ATPase activity returned with a half-life of only $15-20 \mathrm{~h}$ in rats and about $17 \mathrm{~h}$ in dogs. These values are about three times faster than the halflife of the $\alpha$-subunit of the pump (54 h in rats). The newly synthesis of the proton pump is generally greater at night than day and PPIs are less effective during the night. Also, inhibition of the $\mathrm{H}^{+} / \mathrm{K}^{+}$-ATPase can be recovered either by new synthesis of the enzyme or reduction of the disulfide bond between the PPI and the protein (Shin et al., 2006; Hori et al., 2011).

There are some approaches to increase the plasma half-life of the PPIs and improve the acid inhibition. One of them is replacement of the benzimidazole with imidazopyridine for slowing metabolism and prolonging the half-life of PPIs. Tenatoprazole is a good example for this path. It has an important advantage in suppressing of the pump during the night, however its slow activation is a disadvantage for daytime acid suppression. Although this disadvantage, it has been reported that the anti-secretory and anti-ulcer effects of tenatoprazoleare 2-4 times more potent than omeprazole (Liu et al., 2007; Shin and Sachs, 2008).

\section{Adverse Effects and Drug Interactions}

PPIs are relatively safe drugs and very few adverse effects were reported. Nausea, abdominal pain, constipation, flatulence and diarrhea are common side effects in humans (1.5-3\% of patients for omeprazole), but most of these effects are not observed in animals (Kaya, 2007; Papich, 2009; Wallacei and Sharkey, 2011). Säfholm et al. (1994) orally administered at a dose of 0.17 $\mathrm{mg} \mathrm{kg}{ }^{-1}$ to Beagle dogs and a detailed clinical and gastroscopic examination including gastric mucosal biopsy were regularly performed for 7 years. It was concluded that 7 years' treatment with omeprazole in dogs, in a dose resulting in clinically relevant plasma concentrations, did not cause any adverse effects in any of the animals. 
PPIs can inhibit acid secretion completely and it causes a bacterial overgrowth in stomach and intestines. There are several studies regarding PPI induced alterations of the microbiome throughout the gastrointestinal tract (from oral cavity to colon) and its potential results in humans (Freedberg et al., 2014; Tsuda et al., 2015). However, the true cause-effect relationship between PPIs and gastrointestinal bacterial overgrowth has not been established in animals (Kaya 2007; Papich, 2009; Wallacei and Sharkey, 2011; Garcia-Mazcorro et al., 2012) reported that orally administered omeprazole can change the quantitation of various bacteria groups in the gastrointestinal tract of healthy dogs (a decrease in Helicobacter spp. and an increase of other bacteria in the stomach and an increase in Lactobacillus in the duodenum and faeces (only in males)). However, omeprazole administration did not cause major qualitative alteration in the phylogenetic composition of the stomach and the duodenum. The authors noticed that detailed experiments should be performed for the investigation of clinical importance of these findings (Garcia-Mazcorro et al., 2012).

Bacterial growth in stomach as a result of gastric acid suppression may also produce a risk of aspiration pneumonia (aspiration of stomach content) in animals. It could be observed particularly in dogs with megaesophagus (Papich, 2009).

Another important risk is gastric tumors after the long-term usage of PPIs in animals. Because, lack of negative feedback produces higher gastrin levels and it has increased risk of gastric tumors in rats. However, there is no unequivocal evidence about this adverse effect in domestic animals and humans (Kaya, 2007; Papich, 2009; Wallacei and Sharkey, 2011).

It was reported that long-term use of PPIs may increase the fracture risk and side effects on bone mineral density in humans and experimental animals. The reasons of these effects were reported as hypochlorhydria, reduced intestinal calcium absorption and subsequent negative calcium balance caused by PPIs. The possibility of fracture risk is particularly important in horses treated by PPIs (Caston et al., 2015; Yanagihara et al., 2015). However, a recent study showed that administration of omeprazole for 60 days was not significantly affect serum total calcium and ionized serum calcium concentrations and bone density or bone mineral density in normal horses (Caston et al., 2015).

PPIs may also cause some abnormalities in blood biomarkers, due to decreasing of the gastric $\mathrm{pH}$ (Mélo et al., 2014). This issue has not been widely investigated in animals, but Mélo et al. (2014) reported that a maximum of 11 days oral administration of omeprazole affected biomarkers corporated with digestion and lipid, protein and mineral metabolism in healthy horses. However, detailed and longer studies should be carried out for evaluation of the clinical importance of the changes of the blood parameters.

Since PPIs are metabolized by hepatic CYPs, they may interfere with many drugs. PPIs decreased excretion of some drugs by bile, such as warfarin, diazepam and phenytoin. Also, omeprazole can adversely interact with anticlotting agent, clopidogrel and inhibit conversion of this agent to the active anticoagulant form. But, these problems were determined in humans and the clinical significance in veterinary medicine has not been investigated. Because of the acid suppression, oral availability of vitamin B12, itroconazole, ketoconazole and domperidone which need a low $\mathrm{pH}$ for the absorption, may decrease (Kaya, 2007; Papich, 2009; Wallacei and Sharkey, 2011).

\section{Clinical Use in Veterinary Medicine}

PPIs are used for treatment of gastrointestinal disorders generally in dogs and horses. However, indications of PPIs are also reported in other species. Common clinical use of PPIs is shown in Table 2.

PPIs and particularly omeprazole are widely used in dogs for potent and long-acting gastric acid suppression. It is also very effective in dogs with NSAID-induced ulcers and in case of insufficient effectiveness of other antiulcer drugs (Papich, 2009; Tolbert et al., 2011). Preventive effects of omeprazole on the exercise-induced gastric lesions in racing dogs were found superior to famotidine and routine administration of omeprazole was recommended to prevent stress-associated gastric disease in exercising and racing dogs (Davis et al., 2003; Williamson et al., 2010). Also, it was reported that the preoperative administration of omeprazole $\left(1 \mathrm{mg} \mathrm{kg}^{-1}\right.$ $\mathrm{PO}$, at least $4 \mathrm{~h}$ before the operation) is effective in reducing the incidence of gastro-oesophageal reflux during anaesthesia in dogs (Panti et al., 2009). Common oral form of omeprazole is capsules containing granules. This form protects the drug from acid degradation. Usage of PPIs in cats is not common compared to dogs. But, PPIs are considered as safe drugs in cats and generally used similar doses to those used in dogs (Table 2) (Kaya, 2007; Papich, 2009).

Omeprazole is also used for therapy and prophylaxis of ulcers in horses. Generally, $1 \mathrm{mg} / \mathrm{kg} /$ day dose is needed for inhibition of gastric acid suppression. However, common dose is orally $4 \mathrm{mg} / \mathrm{kg} /$ day for 4 weeks for treatment and 2 $\mathrm{mg} / \mathrm{kg} /$ day for prevention of the ulcers (Table 2) (Kaya, 2007; Papich, 2009; Rabuffo et al., 2009). Omeprazole is effective with healing rates of $73-80 \%$ and improvement rates of up to $92 \%$ following 25 to 56 days of treatment in horses with ulcers (Kerbyson et al., 2016). In addition, orally single doses of 40 or $80 \mathrm{mg}$ of esomeprazole magnesium (Nexium) was investigated in horses with gastric ulcer syndrome and both doses were found effective in elevating the $\mathrm{pH}$ of the gastric secretion above the recommended 
threshold $(\mathrm{pH} 4)$ and maintaining the elevated $\mathrm{pH}$ level $(\mathrm{pH}>5)$ in $100 \%$ of the measurement times. Esomeprazole could be an alternative for treatment of gastric ulcers in horses, however further clinical studies are needed (Pereira et al., 2009). Oral paste is usually used pharmaceutical form of PPIs in horses (Papich, 2009; Rabuffo et al., 2009).

\section{Other Uses of PPIs}

Beside the regular clinical usage of PPIs, some other effects or combination with other drugs have been evaluated generally in experimental animals. For example, a combination of a gamma-aminobutyric acid derivative (baclofen) and omeprazole was investigated for the treatment of reflux esophagitis in rats. The beneficial effects of the combination on the healing of the esophagitis were determined (Khinchi et al., 2014).

An important recent research topic regarding PPIs is their effects on preventing anti-cancer drug resistance. Chemoresistance is one of the biggest challenges in cancer therapy. There are several factors of anti-cancer drug resistance, such as impaired drug uptake, increased drug efflux, deletion of receptors, altered drug metabolism, quantitative and qualitative alterations in drug targets, increased DNA damage repair and various mechanisms of anti-apoptosis (Taylor et al., 2015). In addition, recent studies showed that another reason of the chemoresistance is the highly acidic microenvironment of tumors. Almost all anti-cancer drugs are weak bases and they are quickly protonated and neutralized in this acidic environment (Daniel et al., 2013; Taylor et al., 2015; Walsh et al., 2015; Chueca et al., 2016). In this frame, to be provide the increased $\mathrm{pH}$ of the tumor microenvironment may be a good strategy and PPIs may be used for buffering the acidic $\mathrm{pH}$ and enhancing tumor chemosensitivity (Daniel et al., 2013; Spugnini et al., 2011; 2014; Taylor et al., 2015; Walsh et al., 2015; Chueca et al., 2016). There are in vitro studies regarding positive effects of PPIs on the enhancing the sensitivity of neoplastic agents (Luciani et al., 2004; Azzarito et al., 2015; Chueca et al., 2016). Also, positive effects of PPIs against chemoresistance in cancer treatment were reported in veterinary clinical trials. Spugnini et al. (2011) administered high dose of lansoprazole to 27 dogs and 7 cats with different neoplasms. Lansprazole was applied $5 \mathrm{mg} / \mathrm{kg} /$ day for three days after each chemotherapy administration. After the first medication lansprazole was administered $1 \mathrm{mg} / \mathrm{kg}$ /day to prevent gastric hyperacidity rebound for four days. The results showed that high dose lansoprazole induced reversal of tumor chemoresistance and most of the treated animals were well tolerated. Another study of the same group, lansoprozole was applied at the dose of $5 \mathrm{mg} \mathrm{kg}^{-1}$ from Monday to Wednesday and $1 \mathrm{mg} \mathrm{kg}^{-1}$ from Thursday to Sunday, combined with metronomic chemotherapy to 22 dogs and 2 cats with different solid tumors over a 30 months period. Similarly, administration of PPIs was well tolerated and benefical to increase tumor response to metronomic chemotherapy (Spugnini et al., 2014). Walsh et al. (2015) reported a case report regarding beneficial effects of addition of PPIs in cancer therapy. A 15 year old dog with bronchogenic carcinoma was treated metronomic chemotherapy with alkalinisation (a combination of daily cyclophosphamide, proxicam, lansoprazole and a water alkalizer). The patient well tolerated the therapy and it was in a stable condition of disease after 14 months.

These results are very promising data for more effective therapy of cancers with PPIs in animals as well as in humans. However further studies are needed to add PPIs in the regular therapy protocol of different carcinoma types.

PPIs also have anti-inflammatory effects. PPIs have anti-oxidant properties and direct effects on neutrophils, monocytes and other endothelial and epithelial inflammation cells (Kedika et al., 2009). Also, protective effects of omeprazole on gastric mucosal of cirrhotic portal hypertension were investigated in rats and it was found that omeprazole played a protective role in the gastric mucosa by improving the gastric environment, through the influence of inflammatory cytokines to slow down its further damage the gastric mucosa (Gao et al., 2014). However, the anti-inflammatory effect mechanisms of PPIs are not well established, in vivo studies are not sufficient and therefore further investigations are needed to prove the role of PPIs as anti-inflammatory agents (Kedika et al., 2009).

\section{Conclusion}

PPIs are used for treatment of many gastrointestinal disorders in animals as well as humans. All PPIs have similar chemical structure and effectiveness. PPIs are prodrugs and they must be converted to active forms in the body for gastric acid inhibition. Because of the $\mathrm{H}^{+} / \mathrm{K}^{+}$ ATPase is the last stage of the gastric acid secretion, PPIs are accepted as more effective than receptor antagonists in suppressing gastric acid secretion. After the oral administration, PPIs are rapidly and highly absorbed and metabolized. Half-lives of PPIs are short, except tenatoprazole. PPIs are relatively safe drugs and very few adverse effects were reported. Although their some side effects, such as a bacterial overgrowth in stomach and intestines, these adverse effects are not so important in the clinical practice. PPIs are metabolized by hepatic CYPs, therefore they may interfere with many drugs.

Omeprazole is the common PPI in veterinary medicine. Omeprazole and other PPIs are used for long-acting gastric acid suppression and treatment of ulcers, particularly in dogs and horses. Also, some other usage areas, such as prevent the resistance to 
anti-cancer drugs and therapy of some inflammations have been investigated. These researches are very valuable for the future but further studies are needed for a detailed evaluation.

\section{Author's Contribution}

The authors contributed equally in the preparation, development and publication of this manuscript.

\section{Ethics}

This article is original and contains unpublished material. The corresponding author confirms that all of the other authors have read and approved the manuscript and no ethical issues involved.

\section{References}

Azzarito, T., G. Venturi, A. Cesolini and S. Fais, 2015. Lansoprazole induces sensitivity to suboptimal doses of paclitaxel in human melanoma. Cancer Lett., 356: 697-703. DOI: 10.1016/j.canlet.2014.10.017

Caston, S.S., D.C. Fredericks, K.D. Kersh and C. Wang, 2015. Short-Term omeprazole use does not affect serum calcium concentrations and bone density in horses. J. Equine Vet. Sci., 35: 714-723. DOI: 10.1016/j.jevs.2015.07.003

Chueca, E., N. Apostolova, J.V. Esplugues, M.A. Garcia-Gonzalez and A. Lanas et al., 2016. Proton pump inhibitors display antitumor effects in Barrett's Adenocarcinoma Cells. Frontiers Pharmacol. DOI: 10.3389/fphar.2016.00452

Daniel, C., C. Bell, C. Burton, S. Harguindey and S.J. Reshkin et al., 2013. The role of proton dynamics in the development and maintenance of multidrug resistance in cancer. Biochim. Biophys. Acta, 1832: 606-617. DOI: 10.1016/j.bbadis.2013.01.020

Davis, M.S., M.D. Willard, S.L. Nelson, S.M. McCullough and R.E. Mandsager et al., 2003. Efficacy of omeprazole for the prevention of exercise-induced gastritis in racing Alaskan Sled Dogs. J. Vet. Internal Med., 17: 163-166.

Freedberg, D.E., B. Lebwohl and J.A. Abrams, 2014. The impact of proton pump inhibitors on the human gastrointestinal microbiome. Clin. Laboratory Med., 34: 771-785. DOI: 10.1016/j.cll.2014.08.008

Gao, W., H.Y. Li, L.X. Wang, L.J. Hao and J.L. Gao et al., 2014. Protective effect of omeprazole on gastric mucosal of cirrhotic portal hypertension rats. Asian Pacific J. Tropical Med., 7: 402-406. DOI: 10.1016/s1995-7645(14)60065-1

Garcia-Mazcorro, J.F., J.S. Suchodolski, K.R. Jones, S.C. Clark-Price and S.E. Dowd et al., 2012. Effect of the proton pump inhibitor omeprazole on the gastrointestinal bacterial microbiota of healthy dogs. FEMS Microbiol. Ecol., 80: 624-636. DOI: $10.1111 / \mathrm{j} .1574-6941.2012 .01331 . \mathrm{x}$
Hori, Y., J. Matsukawa, T. Takeuchi, H. Nishida and M. Kajino et al., 2011. A study comparing the antisecretory effect of TAK-438, a novel potassiumcompetitive acid blocker, with lansoprazole in animals. J. Pharmacol. Exp. Therapeut., 337: 797-804. DOI: 10.1124/jpet.111.179556

Huttunen, K.M., H. Raunio and J. Rautio, 2011. Prodrugs-from serendipity to rational design. Pharmacol. Rev., 63: 750-771. DOI: $10.1124 /$ pr.110.003459

Kaya, S., 2007. Sindirim Sistemi Farmakolojisi. In: Veteriner Farmakoloji, Cilt 2, Baskı 4, Kaya, S. (Ed.), Medisan Yayınevi, Ankara, pp: 181-232.

Kedika, R.R., R.F. Souza and S.J. Spechler, 2009. Potential anti-inflammatory effects of proton pump inhibitors: A review and discussion of the clinical implications. Digestive Dis. Sci., 54: 2312-2317. DOI: $10.1007 / \mathrm{s} 10620-009-0951-9$

Kerbyson, N.C., D.K. Knottenbelt, H.B. Carslake, R.C. Conwell and D.G.M. Sutton et al., 2016. A comparison between omeprazole and a dietary supplement for the management of squamous gastric ulceration in horses. J. Equine Vet. Sci., 40: 94-101. DOI: $10.1016 /$ j.jevs.2016.02.228

Khinchi, P., S. Saha, S.A. Saraf and G. Kaithwas, 2014. Combination therapy of gamma-aminobutyric acid derivative promotes proton pump inhibitor based healing of reflux esophagitis in animal model. Pharmacol. Rep., 66: 165-168. DOI: $10.1016 /$ j.pharep.2013.06.011

Kosma, C.I., D.A. Lambropoulou and T.A. Albanis, 2016. Analysis, occurrence, fate and risks of proton pump inhibitors, their metabolites and transformation products in aquatic environment: A review. Sci. Total Environ., 569-570: 732-750. DOI: $10.1016 /$ j.scitotenv.2016.06.160

Kosugi, Y., S. Yamamoto, N. Sano, A. Furuta and T. Igari et al., 2015. Evaluation of acid tolerance of drugs using rats and dogs controlled for gastric acid secretion. J. Pharmaceutical Sci., 104: 2887-2893. DOI: $10.1002 /$ jps.24401

Liu, P., B. Sun, X. Lu, F. Qin and F. Li, 2007. HPLC determination and pharmacokinetic study of tenatoprazole in dog plasma after oral administration of enteric-coated capsule. Biomed. Chromatography, 21: 89-93. DOI: 10.1002/bmc.724

Luciani, F., M. Spada, A. De Milito, A. Molinari and L. Rivoltini et al., 2004. Effect of proton pump inhibitor pretreatment on resistance of solid tumors to cytotoxic drugs. J. Nat. Cancer Inst., 96: 17021713. DOI: $10.1093 /$ jnci/djh305

Mélo, S.K.M., T.A. Santiago, T.D.L. Duarte, J.M.G. Abreu and H.C. MansoFilho, 2014. A proton-pump unhibitor modifies the concentration of digestion biomarkers in healthy horses. J. Equine Vet. Sci., 34: 1318-1323. DOI: 10.1016/j.jevs.2014.09.013 
Ortiz de Garcia, S.A., G. Pinto Pinto, P.A. Garcia-Encina and R. Irusta-Mata, 2014. Ecotoxicity and environmental risk assessment of pharmaceuticals and personal care products in aquatic environments and wastewater treatment plants. Ecotoxicology, 23: 1517-1533. DOI: 10.1007/s10646-014-1293-8

Panti, A., R.C. Bennett, F. Corletto, J. Brearley and N. Jeffery et al., 2009. The effect of omeprazole on oesophageal $\mathrm{pH}$ in dogs during anaesthesia. J. Small Anim. Pract., 50: 540-544. DOI: $10.1111 / \mathrm{j} .1748-5827.2009 .00818 . \mathrm{x}$

Papich, M.G., 2009. Drugs Affecting Gastrointestinal Function. In: Veterinary Pharmacology and Therapeutics, Riviere, J.E. and M.G. Papich (Eds.), John Wiley and Sons, Ames, ISBN-10: 0813820618, pp: 1247-1272.

Pereira, M.C., F.L. Levy, C.A.A. Valadão, G.C. Ferraz and A. Queiroz-Neto, 2009. Preliminary study of the gastric acidity in thoroughbred horses at rest after enteral administration of esomeprazole magnesium (Nexium). J. Equine Vet. Sci., 29: 791-794. DOI: 10.1016/j.jevs.2009.10.006

Rabuffo, T.S., E.S. Hackett, N. Grenager, R. Boston and J.A. Orsini, 2009. Prevalence of gastric ulcerations in horses with colic. J. Equine Vet. Sci., 29: 540-546. DOI: $10.1016 /$ j.jevs.2009.05.005

Säfholm, C., N. Havu, H. Forssell, G. Sundell and H. Mattsson, 1994. Effect of 7 years' daily oral administration of omeprazole to Beagle Dogs. Digestion, 55: 139-147.

Scarpignato, C. and I. Pelosini, 2006. Review article: The opportunities and benefits of extended acid suppression. Alimentary Pharmacol. Therapeut., 23: 23-34. DOI: 10.1111/j.1365-2036.2006.02945.x

Shin, J.M., M. Homerin, F. Domagala, H. Ficheux and G. Sachs, 2006. Characterization of the inhibitory activity of tenatoprazole on the gastric $\mathrm{H}^{+}, \mathrm{K}^{+}$-ATPase in vitro and in vivo. Biochem. Pharmacol., 71: 837849. DOI: $10.1016 /$ j.bcp.2005.11.030

Shin, J.M. and G. Sachs, 2004. Differences in binding properties of two proton pump inhibitors on the gastric $\mathrm{H}^{+}, \mathrm{K}^{+}$-ATPase in vivo. Biochem. Pharmacol., 68: 2117-2127. DOI: 10.1016/j.bcp.2004.07.035

Shin, J.M. and G. Sachs, 2008. Pharmacology of proton pump inhibitors. Curr. Gastroenterol. Rep., 10: 528-534.

Spugnini, E.P., A. Baldi, S. Buglioni, F. Carocci and G. Milesi de Bazzichini et al., 2011. Lansoprazole as a rescue agent in chemoresistanttumors: A phase I/II study in companion animals with spontaneously occurring tumors. J. Transl. Med., 9: 1-12.
Spugnini, E.P., S. Buglioni, F. Carocci, F. Menicagli and B. Vincenzi et al., 2014. High dose lansoprazole combined with metronomic chemotherapy: A phase I/II study in companion animals with spontaneously occurring tumors. J. Transl. Med., 12: 1-10.

Taylor, S., E.P. Spugnini, Y.G. Assaraf, T. Azzarito and C. Rauch et al., 2015. Microenvironment acidity as a major determinant of tumor chemoresistance: Proton Pump Inhibitors (PPIs) as a novel therapeutic approach. Drug Resistance Update, 23: 69-78. DOI: 10.1016/j.drup.2015.08.004

Tolbert, K., S. Bissett, A. King, G. Davidson and M. Papich et al., 2011. Efficacy of oral famotidine and 2 omeprazole formulations for the control of intragastric $\mathrm{pH}$ in dogs. J. Vet. Internal Med., 25: 47-54.

Tsuda, A., W. Suda, H. Morita, K. Takanashi and A. Takagi et al., 2015. Influence of proton-pump 1nhibitors on the luminal microbiota in the gastrointestinal tract. Clin. Trans. Gastroenterol. DOI: $10.1038 / \operatorname{ctg} .2015 .20$

Wallacei, J.L. and K.A. Sharkey, 2011. Pharmacotherapy of Gastric Acidity, Peptic Ulcers and Gastroesophageal Reflux Disease. In: Goodman and Gilman's The Pharmacological Basis of Therapeutics, Brunton, L.L., B.A. Chabner and B.C. Knollmann (Eds.), McGraw-Hill Education, New York, ISBN-10: 0071624422, pp: 1309-1322.

Walsh, M., S. Fais, E.P. Spugnini, S. Harguindey and T. Abu Izneid et al., 2015. Proton pump inhibitors for the treatment of cancer in companion animals. J. Exp. Clin. Cancer Res., 34: 1-9.

DOI: $10.1186 / \mathrm{s} 13046-015-0204-\mathrm{Z}$

Williamson, K.K., M.D. Willard, M.E. Payton and M.S. Davis, 2010. Efficacy of omeprazole versus high-dose famotidine for prevention of exercise1nduced gastritis in racing Alaskan Sled Dogs. J. Vet. Internal Med., 24: 285-288. DOI: $10.1111 /$ j.1939-1676.2009.0454.x

Yanagihara, G.R., A.G. de Paiva, M.P. Neto, L.H. Torres and A.C. Shimano et al., 2015. Effects of longterm administration of omeprazole on bone mineral density and the mechanical properties of the bone. Revista Brasileira de Ortopedia, 50: 232-238. DOI: 10.1016/j.rboe.2015.03.002

Zullo, A., V. De Francesco and C. Hassan, 2012. Predicting Helicobacter pylori eradication how to teach an old dog new tricks! J. Clin. Gastroenterol., 46: 259-261. 